\title{
Thalamic Connections of Two Functional Subdivisions of the Somatosensory Forepaw Cerebral Cortex of the Raccoon
}

\author{
Gernot S. Doetsch, ${ }^{1}$ Gregg P. Standage, ${ }^{2}$ Kim W. Johnston, ${ }^{3}$ and Chia-Sheng Lin ${ }^{4}$ \\ ${ }^{1,3}$ Department of Surgery (Section of Neurosurgery), ${ }^{1}$ Department of Physiology and Endocrinology, and ${ }^{2}$ Department of \\ Anatomy, Medical College of Georgia, Augusta, Georgia 30912, and 4Department of Anatomy, Duke University Medical \\ Center, Durham, North Carolina 27710
}

The purpose of this study was to compare the thalamic interconnectivities of 2 functionally distinct subdivisions of the somatosensory (Sml) forepaw cortex of the raccoon-the somatotopic subdivision representing the glabrous skin of the digits and the more heterogeneous subdivision representing the hairy skin and claws. Injections of HRP were made into one or the other functional subdivision of a specific digit subgyrus of Sml cortex in 10 adult raccoons. The distribution of HRP-labeled neurons and axon terminals in the thalamus revealed that the 2 sectors have different patterns of thalamic projections. The glabrous skin region of each cortical digit zone was interconnected with a specific crescent-shaped lamella of neurons that extended rostrocaudally through the ventral posterior lateral (VPL) nucleus and typically was separated from adjacent lamellae by small bundles of myelinated fibers. The VPL lamellae constituted relatively distinct digit subnuclei that were connected somatotopically with the glabrous subdivisions of the corresponding cortical digit areas. The projections were dense, topographic, and reciprocal; labeled neurons and axon terminals within a particular lamella overlapped considerably and tended to be arranged in clusters. In contrast, the heterogeneous region of each cortical digit zone was reciprocally connected with the somatotopically appropriate VPL digit subnucleus and with adjoining subnuclei as well. The projections were comparatively sparse, less topographic, and more widely distributed than those of the glabrous skin sectors; groups of HRP-positive neurons and terminals in VPL tended to straddle the borders of the appropriate lamella and extended into adjacent lamellae. Furthermore, small clusters of labeling were found in the dorsal, presumed kinesthetic region of VPL and in portions of the ventral posterior inferior nucleus and the posterior nucleus.

These results indicate that the glabrous cortical subdivisions have precise, somatotopically organized connections with specific VPL subnuclei, whereas the heterogeneous

\footnotetext{
Received Dec. 29, 1986; revised Oct. 23, 1987; accepted Oct. 26, 1987.

We are grateful to Matthew Wright, William Keldahl, and Paula Wade for their tcchnical assistance during the experiments and for their help in analyzing the data. We thank Max Blanco for his photographic work and Tina DeVore and Brenda Phillips for typing the manuscript. We express our sincere appreciation to Laura McKie for preparing the preliminary and final versions of the illustrations.

This research was supported primarily by Grant BNS-8419035 to GSD from the National Science Foundation. Additional support was obtained from Grants NS21935 to GPS and NS06233 in C.-SI from the National Institutes of Health

Correspondence should be addressed to Dr. Doetsch at the above address.

Copyright (C) 1988 Society for Neuroscience $0270-6474 / 88 / 061873-14 \$ 02.00 / 0$
}

cortical subdivisions have more diffuse and scattered connections with several subregions of VPL and other thalamic nuclei as well. These 2 thalamocortical projection patterns may account for many of the differing functional properties of neurons residing within the 2 cortical sectors. Finally, the convergent thalamic projections to the heterogeneous cortical regions could contribute, at least indirectly, to the functional reactivation that occurs within $\mathrm{Sml}$ cortex of the raccoon following peripheral nerve transection (Kelahan and Doetsch, 1984).

The somatosensory system of the raccoon has attained a remarkable degree of evolutionary development and constitutes a unique model for studying the properties of the dorsal columnmedial lemniscus pathway under normal and experimentally altered conditions. Large and highly differentiated representations of the cutaneous surfaces of the forepaw digits are found within the cuneate nucleus of the medulla (Johnson et al., 1968), the ventral posterior lateral (VPL) nucleus of the thalamus (Welker and Johnson, 1965), and the primary somatosensory (SmI) cortex which receives the major projections from VPL (Welker and Seidenstein, 1959). Each digit representation in the cuneate and VPL nuclei forms a lamellar subnucleus that is segregated, more or less, from its neighbors by small bundles of myelinated fibers. In SmI cortex, each digit is represented with in a different and distinct subgyrus, located lateral, anterior, or medial to the triradiate sulcus; the palmar pads are represented in an orderly sequence posterio ? this sulcus.

The cortical area (zone) for a given (iggit consists of at least 2 major subdivisions or sectors, a relatively homogeneous posterior region representing only the globicus skin and a more heterogeneous anterior region represening both the hairy skin and claw. Electrophysiological mapping siudies have shown that neurons within the glabrous skin sectoi are modality-specific and have small, somatotopically organized receptive fields (RFs), while neurons within the hairy skin and claw sector have larger RFs that are less somatotopic and may involve combinations of hairy skin and claws and, occasionally, glabrous skin or deep tissues (Johnson et al., 1982; Kelahan and Doetsch, 1984; Johnson, 1985). Bccausc of its more diverse and convergent functional properties, the latter subdivision has been referred to as the "heterogeneous" region by Johnson et al. (1982). Located anterior to this subdivision of SmI cortex is a functionally separate region-designated as the "kinesthetic" area-that receives input from muscle and joint afferents, occasionally mixed with input from cutaneous receptors (Johnson et al., 1982; Feld- 

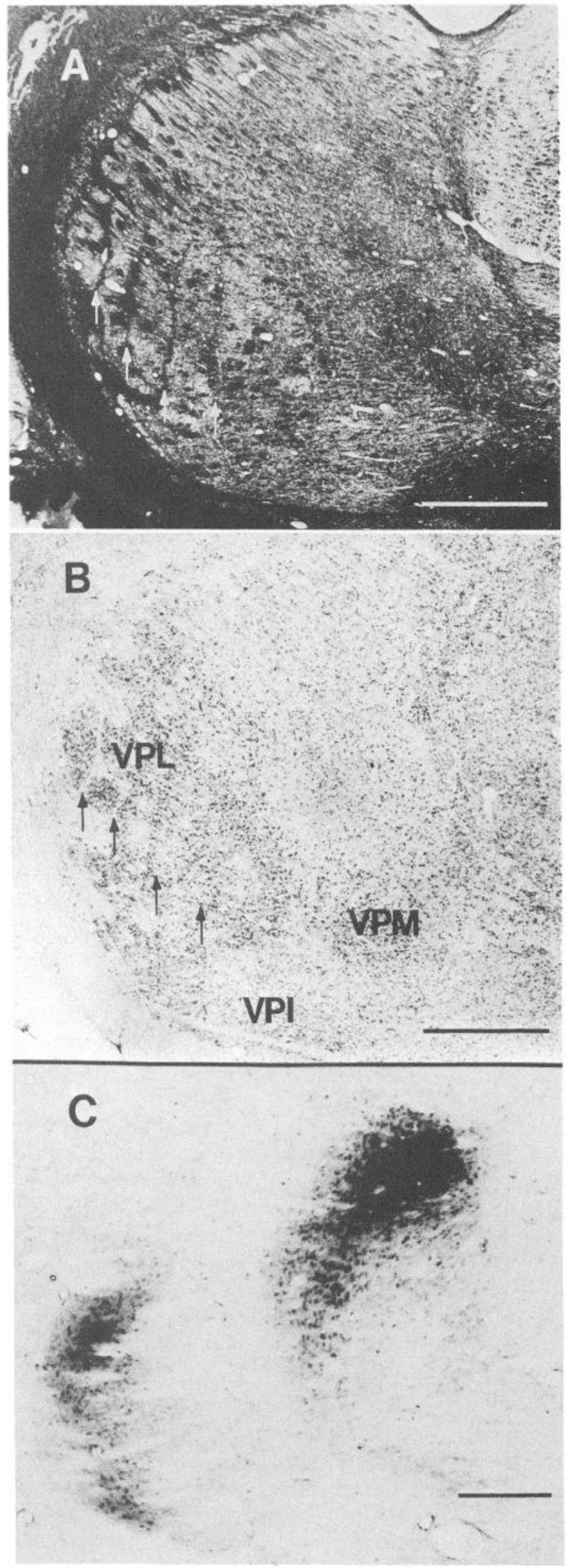

Figure 1. Photomicrographs showing the lobulation and lamellar organization of the VPL nucleus of the thalamus. Neighboring sections of the left thalamus were stained for myelin $(A)$ and Nissl substance $(B)$; scale in $A$ and $B, 2 \mathrm{~mm}$. Arrows point to fiber bundles separating lamellae that represent different forepaw digits. $C$, Two HRP-labeled subnuclei in the left VPL representing digit 2 medially and digit 4 laterally fol- man and Johnson, 1985; Johnson, 1985). This cortical area is the target of thalamic projections from a separate kinesthetic region of VPL (Wiener et al., 1987) that may correspond to the ventral posterior oral (VPO) nucleus of other species (Kaas, 1983; Dykes et al., 1986). More rostrally, the kinesthetic area borders on primary motor (MsI) cortex as defined by electrical stimulation of the cortical surface (Hardin et al., 1968) and electrophysiological activation of the pyramidal tract (Ray and Doetsch, 1977). The motor cortex of the raccoon is interconnected predominantly with the ventral lateral (VL) nucleus of the thalamus (Sakai, 1982).

The functional organization of the glabrous skin representations of SmI cortex is consistent with the orderly projections from different digit subnuclei in VPL of the thalamus to specific digit subgyri within SmI cortex, originally described by Welker and Johnson (1965) and recently confirmed with anatomical tracer methods (Herron, 1983; Warren and Pubols, 1984; Rasmusson and Nance, 1986). However, the pattern of thalamocortical projections to the heterogeneous cortical representations of the hairy skin and claws has not been reported.

Previous studies by Doetsch and his colleagues (Carson et al., 1981; Kelahan et al., 1981; Kelahan and Doetsch, 1984) have shown that in adult raccoons transection of the cutaneous nerves of a single forepaw digit (by amputation) causes dramatic timedependent changes in the functional organization of the corresponding digit representation within SmI cortex. Less than 24 $\mathrm{hr}$ after removal of the third digit, neurons originally responsive only to stimulation of digit 3 began to respond to stimulation of digit 2 and digit 4 and, to a lesser extent, the other 2 digits or the palmar pads. The "novel" RFs of neurons within the glabrous subdivision of the reactivated digit zone were larger and less topographically organized than normal and often involved mixtures of glabrous skin, hairy skin, or claws, thus obliterating the distinction between the glabrous and heterogeneous cortical sectors. Indeed, the new convergent response properties observed after digit removal are reminiscent of those found normally in the heterogeneous subdivisions. Similar injury-induced changes in SmI cortex of the raccoon have been reported by Rasmusson (1982) and Rasmusson et al. (1985).

Since cortical reactivation can occur within $1 \mathrm{~d}$ after digital nerve transection and involves an extensive cortical area $(>25$ $\mathrm{mm}^{2}$ ), the functional changes must be due primarily to the physiological unmasking or release of preexisting anatomical connections rather than to central axonal sprouting and synaptogenesis (Kelahan and Doetsch, 1984). The unmasking of synaptic connections could occur at subcortical levels and simply be reflected cortically, or they may take place within SmI cortex itself-involving thalamocortical projections or local cortical interconnections. The rationale of this study was to identify the anatomical interconnections that might support functional reactivation within SmI cortex following nerve injury. To address this issue, the thalamic and intracortical connectivities of the glabrous and heterogeneous subdivisions of individual SmI cortical digit representations were studied and compared in adult raccoons using the HRP tracer method. The thalamic interconnections are described in the present paper and the intracortical connections are presented in the following paper (Doetsch et al., 1988).

lowing large HRP injections into the digit 2 and digit 4 subgyri of the ipsilateral SmI cortex (see Fig. 2); scale, $0.5 \mathrm{~mm}$. 


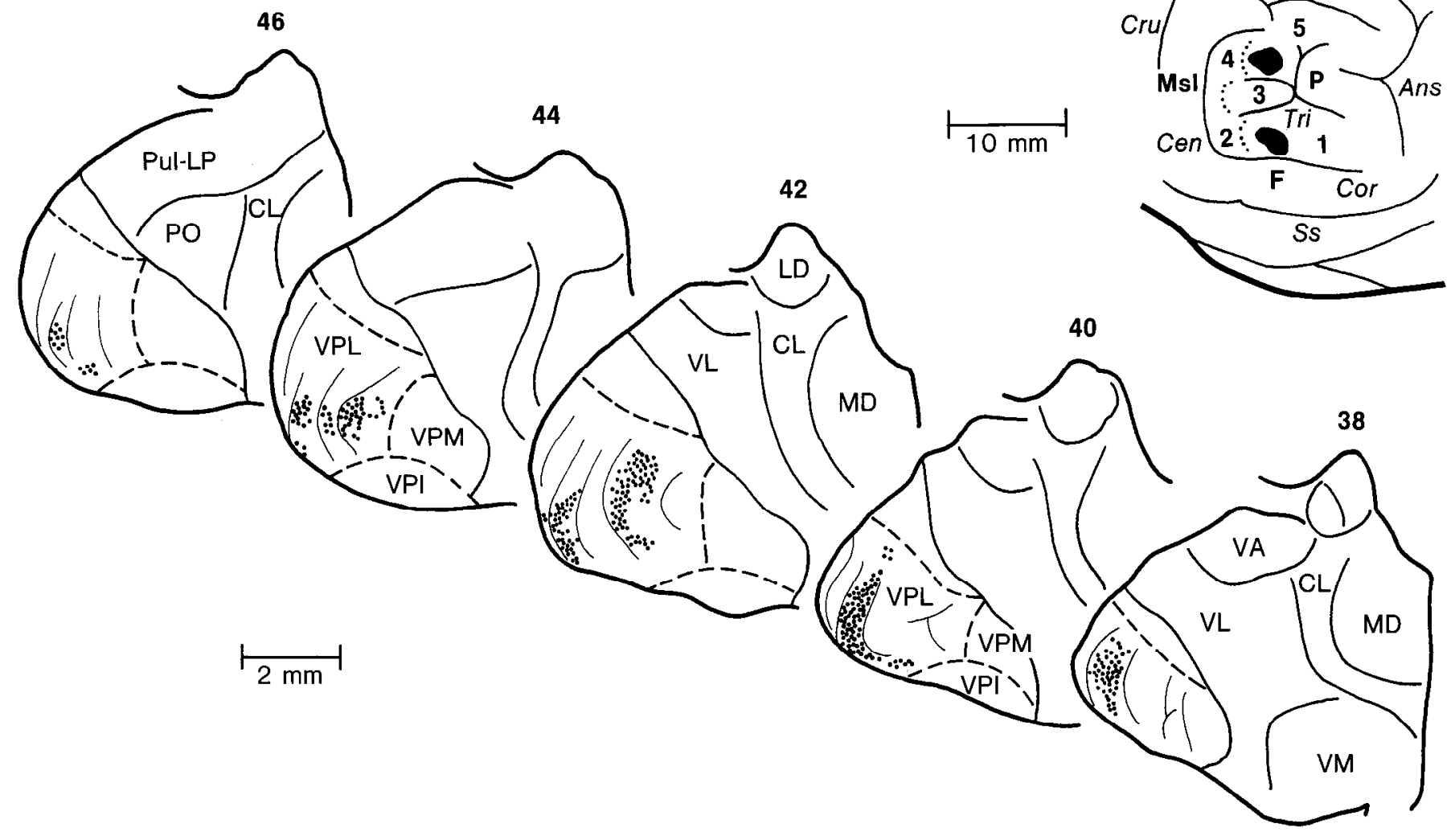

Figure 2. Distribution of labeled neurons in the thalamus rcsulting from 2 large injections of HRP into the glabrous subdivisions of the digit 2 and digit 4 zones of the SmI forepaw cortex. In this and subsequent figures, the core of each HRP injection site is shown in black on a lateral surface view of the brain. The dotted lines on the brain show the average boundaries between the anterior heterogeneous and posterior glabrous cortical subdivisions derived from electrophysiological mapping experiments (see text). Cortical sulci are designated in italics, and functionally or somatotopically different cortical areas are indicated in bold numbers and letters. The locations of HRP-filled neurons are shown by dots on rostrocaudal coronal sections through the thalamus. Major thalamic nuclei are identified; the dashed line in the dorsal portion of VPL marks the approximate ventral border of the kinesthetic region. See Appendix for all nomenclature and abbreviations. Thickness of sections in this case, 60 $\mu \mathrm{m}$; distance between sections illustrated, $600 \mu \mathrm{m}$. There is extensive labeling of cells in 2 nonadjoining VPL lamellae that constitute the subnuclei for digit 2 medially and digit 4 laterally (see Fig. 1C). The small cluster of HRP-filled neurons located in the intervening (digit 3) lamella of section 44 probably resulted from spread of HRP into the adjacent digit 3 subgyrus or into a heterogeneous cortical region.

\section{Materials and Methods}

Data were obtained from 10 adult raccoons (Procyon lotor) of both sexes. Each animal was sedated with ketamine $\mathrm{HCl}(15 \mathrm{mg} / \mathrm{kg}$. IM) and then anesthetized with pentobarbital sodium $(30 \mathrm{mg} / \mathrm{kg}$, IP). The animal's head was secured in a stereotaxic instrument, and bilateral craniotomies were done over the SmI digit cortex of each hemisphere. A small incision was made in the dura mater through which a tungsten microclectrode was inserted into the cortex to map the tissue electrophysiologically. The RFs of small clusters of neurons were determined by cutaneous stimulation of the digits, and the cells were classified according to their sensitivity to stimulation of glabrous skin versus hairy skin or claws. Sufficient $(8-10)$ electrode penetrations were made to identify clearly the digit represented in the exposed cortical subgyrus and to determine the boundary between the glabrous and heterogeneous subdivisions of the digit zone.

Manual pressure injections of a $36 \%$ solution of HRP (Sigma, Type VI) or a mixture of $36 \% \mathrm{HRP}$ with $3 \%$ wheat germ agglutinin-conjugated HRP were made into the electrophysiologically defined cortical digit areas. In the first 5 animals, $0.15-0.6 \mu$ l of HRP was delivered through a $10 \mu 1$ Hamilton syringe. Injections were made at single sites within the digit 2 and digit 4 subgyri of one hemisphere and the digit 3 subgyrus of the opposite hemisphere. In the other 5 animals, 0.01-0.04 $\mu$ linjections were made with a $1 \mu \mathrm{l}$ syringe. Each hemisphere was injected at a single locus within one subgyrus representing digit $2,3,4$, or 5 . With these small injections, special care was taken to confine the HRP either to the glabrous sector or the heterogeneous sector of a given cortical digit zone. This was done by placing each injection near the center of the electrophysiologically defined subdivision (with the bevel of the syringe needle directed away from the adjoining subdivision) at a distance of at least $1-2 \mathrm{~mm}$ from the border separating the two subdivisions. In all cases, the HRP was introduced at depths of 1-2 $\mathrm{mm}$ below the pial surface; the syringe needle was kept in place for about $10 \mathrm{~min}$ prior to withdrawal from the cortical tissue. After completing the injections, the dura mater was sutured to prevent brain herniation, and the muscle and overlying skin werc surgically approximated.

After a survival time of about $48 \mathrm{hr}$, the raccoon was given an overdose of pentobarbital sodium and perfused through the heart with a saline $-0.05 \%$ sodium nitrite rinse. This was followed by a fixative solution consisting of $2.5 \%$ glutaraldehyde and $1.0 \%$ paraformaldehyde in $0.1 \mathrm{M}$ phosphate buffer at $\mathrm{pH} 7.4$ (room temperature) and another rinse of $10 \%$ sucrose in $0.1 \mathrm{M}$ phosphate buffer at $4^{\circ} \mathrm{C}$. The brain was then blocked stereotaxically, removed from the cranium, photographed, and placed in a cold $20 \%$ sucrose-buffer solution; $24 \mathrm{hr}$ later, the brain was transferred to a $30 \%$ sucrose-buffer solution and stored at $4^{\circ} \mathrm{C}$ for $1-3 d$.

The brain was then frozen and sectioned serially in the coronal plane at intervals of $40-60 \mu \mathrm{m}$. Every 5 th or 10 th section was processed for HRP histochemistry using the method of Mesulam (1978) with tetramethyl benzidine as the chromogen. The reacted sections werc staincd with thionin, and adjacent sections were stained with cresyl violet for analysis of cytoarchitecture. 

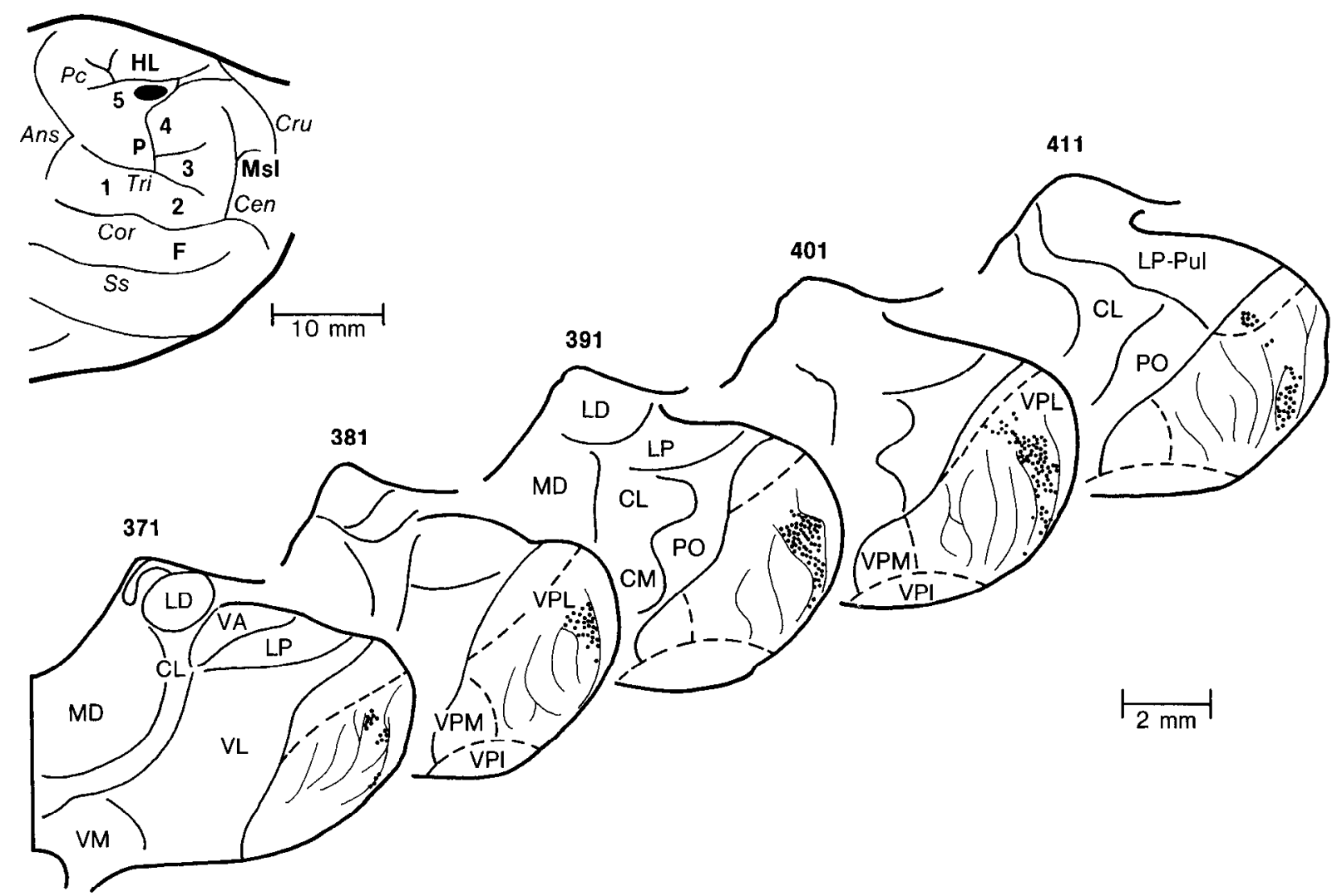

Figure 3. Location of HRP-filled neurons in the thalamus following an injection into the glabrous sector of the digit 5 cortical area. Section thickness, $40 \mu \mathrm{m}$; distance between sections, $400 \mu \mathrm{m}$. Heavy labcling is present in the digit 5 subnucleus of VPL; posteriorly (section 411 ), a small aggregate of HRP-filled cells is located in the presumed kinesthetic region of VPL.

The sections were examined microscopically to determine the presence of HRP reaction product in the thalamus, indicative of retro- or orthograde axonal transport. Camera lucida drawings were made of cortical and thalamic sections under low-power $(6 \times$ and $12 \times$, respectively) magnification; the cortical injection sites were mapped using both bright- and dark-field illumination and were plotted on the drawings. HRP-labeled neurons and axon terminals in the thalamus were identified under high-power (100-250x) magnification using bright- and dark-field illumination, and their distributions were plotted on the drawings.

The boundarics of thalamic nuclei were defined with reference to criteria previously used by Craig and Burton (1985) and reviewed by Jones (1985). The approximate borders of the dorsal, presumed kinesthetic region of VPL were drawn based on recent descriptions of this region by Johnson (1985) and Wiener et al. (1987) (see Appendix).

\section{Results}

The data revealed a fundamental feature of the organization of SmI cortex that has not been described previously. Characteristic differences were found in the thalamic interconnectivity of the glabrous and heterogeneous subdivisions of the SmI cortical digit zones.

\section{Size and location of HRP injection sites}

Each cortical injection site was found to consist of a central core of dense HRP reaction product, surrounded by a more lightly stained halo zone of HRP diffusion (Fig. 6A). The intensely stained central core is commonly believed to constitute the effective site of active uptake and transport of HRP (Jones, 1975; Warr et al., 1981). The digit subgyri receiving large (0.15-0.6 $\mu$ l) injections contained extensive central cores, some of which were confined to the injected subgyrus, while others invaded the bank of an adjoining digit subgyrus. However, all were restricted to the SmI digit cortex, with no spread into the rostral kinesthetic area located in the fundus and anterior bank of the central sulcus (see Fig. 2). In contrast, the subdivisions of individual digit zones receiving small $(0.01-0.04 \mu \mathrm{l}) \mathrm{HRP}$ injections had discrete central cores that were clearly confined to a single digit zone. Each of the cores (with one exception shown in Fig. 3) measured less than $2 \mathrm{~mm}$ in diameter. Therefore, the radius of the effective injection site was smaller than the distance from the center of that site to the electrophysiologically defined boundary of the 2 cortical subdivisions. Furthermore, the injections made into the glabrous sectors were all centered less than $3 \mathrm{~mm}$ anterior to the triradiate sulcus; those in the heterogeneous sectors were all located much closer to the central sulcus, $4-8 \mathrm{~mm}$ rostral to the triradiate sulcus. These data indicate that the small HRP injections-upon which the basic conclusions of this study restwere confined to a preselected cortical subdivision.

\section{General features of thalamocortical interconnections}

The distribution of labeling in the thalamus following HRP injections into the SmI forepaw cortex was basically consistent with the original description by Welker and Johnson (1965) of somatosensory thalamocortical relationships in the raccoon. The VPL nucleus of the thalamus (Fig. 1) was found to have specific, topographically organized interconnections with the SmI forepaw cortex. The fundamental pattern of these connections was evident by comparison of the hemispheres receiving large HRP injections in 2 nonadjacent cortical digit zones (digits 2 and 4) with those receiving injections in a single digit zone (e.g., digit 


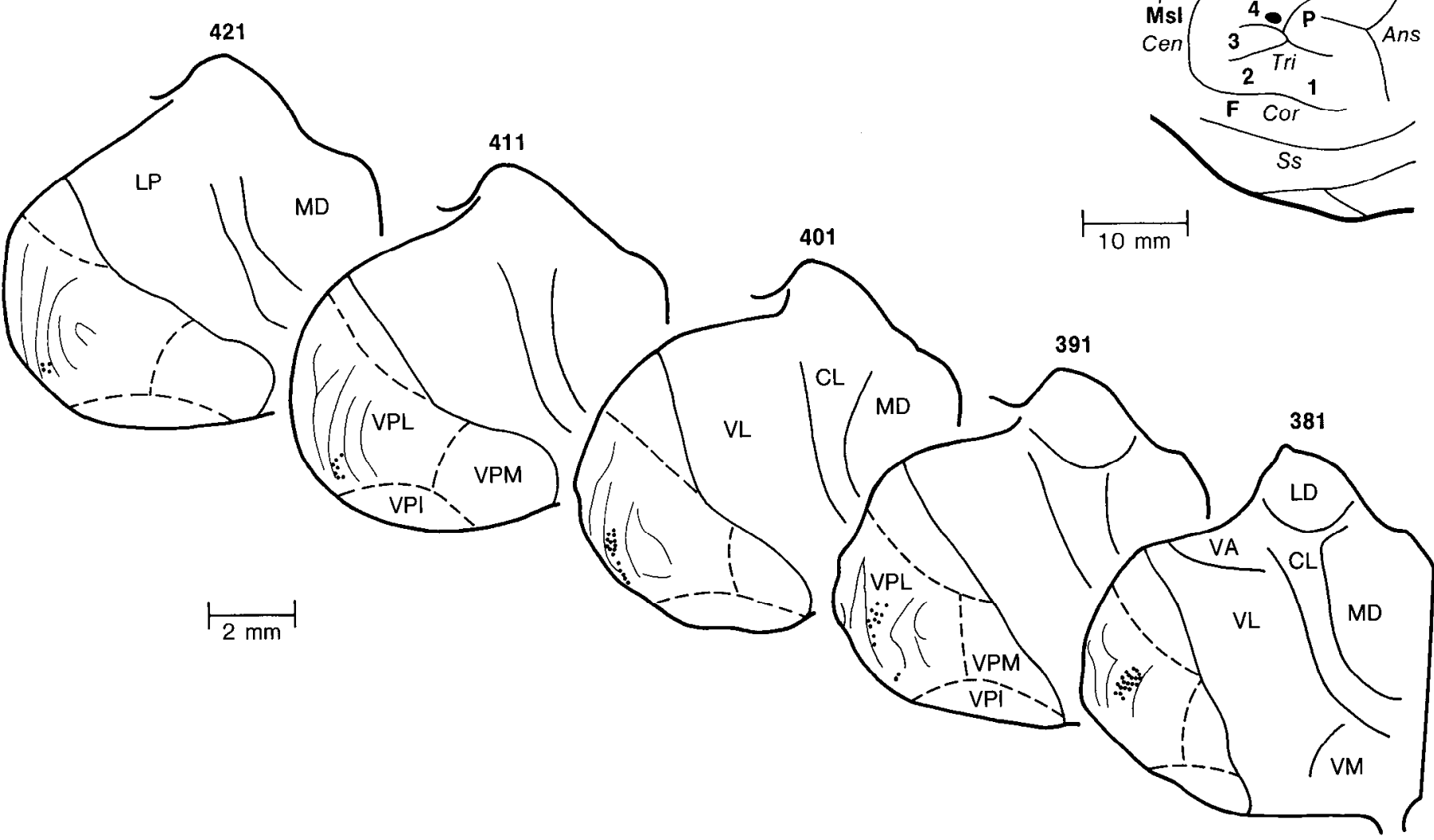

Figure 4. Distribution of labeled neurons in the thalamus produced by a small injection of HRP into the glabrous region of the digit 4 cortical zone. Section thickness, $40 \mu \mathrm{m}$; distance between sections, $400 \mu \mathrm{m}$. Note that HRP-filled cells are clustered and confined to the digit 4 subnucleus of VPL.

3). Each cortical subgyrus representing a particular digit was connected to a different, relatively distinct subnucleus of VPL (Fig. 1, $A, B$ ) that constitutes the thalamic representation of that digit. The VPL subnuclei defined by HRP labeling consisted of aggregates of neurons that formed crescent-shaped lamellae, with their concave edges directed toward the midline (Fig. 1C). Each subnucleus extended rostrocaudally through much of VPL for distances up to 4-5 $\mathrm{mm}$; the maximum dorsoventral and mediolateral dimensions of a given subnucleus were approximately $3 \mathrm{~mm}$ and $1 \mathrm{~mm}$, respectively. Each lamella related to a particular digit was more or less segregated from its neighbors by small vertically-aligned bundles or laminae of myelinated fibers (Fig. 1A).

The basic somatotopic organization of the SmI forepaw cortex and its connectional relationships with digit subnuclei of VPL are illustrated in Figure 2. Large injections $(0.25 \mu \mathrm{l})$ of HRP made in the subgyri representing digits 2 and 4 of the left hemisphere produced extensive labeling of neurons and neuropil in 2 different subnuclei representing these same digits within the ipsilateral VPL. Since the distributions of HRP-filled cells and axon terminals overlapped extensively, only the locations of labeled neurons are shown in this and subsequent figures. As expcctcd, the labcling was almost exclusively confined to the nonadjacent lamellae for digits 2 and 4, separated by the intervening digit 3 lamella that was devoid of label except for a small patch near the caudal region of VPL (see section 44 of Fig. 2). In contrast, following an injection in the digit 3 subgyrus of the right hemisphere (not illustrated), thalamic labeling was confined to the appropriate digit 3 subnucleus of VPL.

In each case involving large HRP injections, the degree to which labeling was restricted to an individual VPL lamella depended directly on how well the HRP was confined to the glabrous subdivision of only one cortical digit zone. The brain in Figure 2 shows the avcrage boundaries between the glabrous and heterogeneous sectors of the cortical areas representing digits 2,3 , and 4 ; these borders were derived from detailed electrophysiological mapping experiments done previously in our laboratory but do not reflect significant differences between individual animals. Spread of HRP from one digit zone to another, or across the boundary separating the 2 subdivisions of any one digit area, usually produced labeling in more than one VPL subnucleus or in other thalamic regions (see below). Nonetheless, the basic pattern of labeling in all of these cases was consistent with the relative locations of the lamellar subdivisions of VPL as first described by Welker and Johnson (1965)-forepaw digits 1-5 were represented in a medial-lateral sequence, with some rostrocaudal staggering so that the (lateral) subnuclei for the ulnar digits were located slightly rostral to the (medial) subnuclei for the radial digits.

\section{Thalamic connections of glabrous skin cortical subdivisions}

Small $(0.01-0.04 \mu \mathrm{l})$ injections of HRP made into the electrophysiologically defined glabrous subdivisions of the cortical digit zones produced patterns of thalamic labeling that conformed 

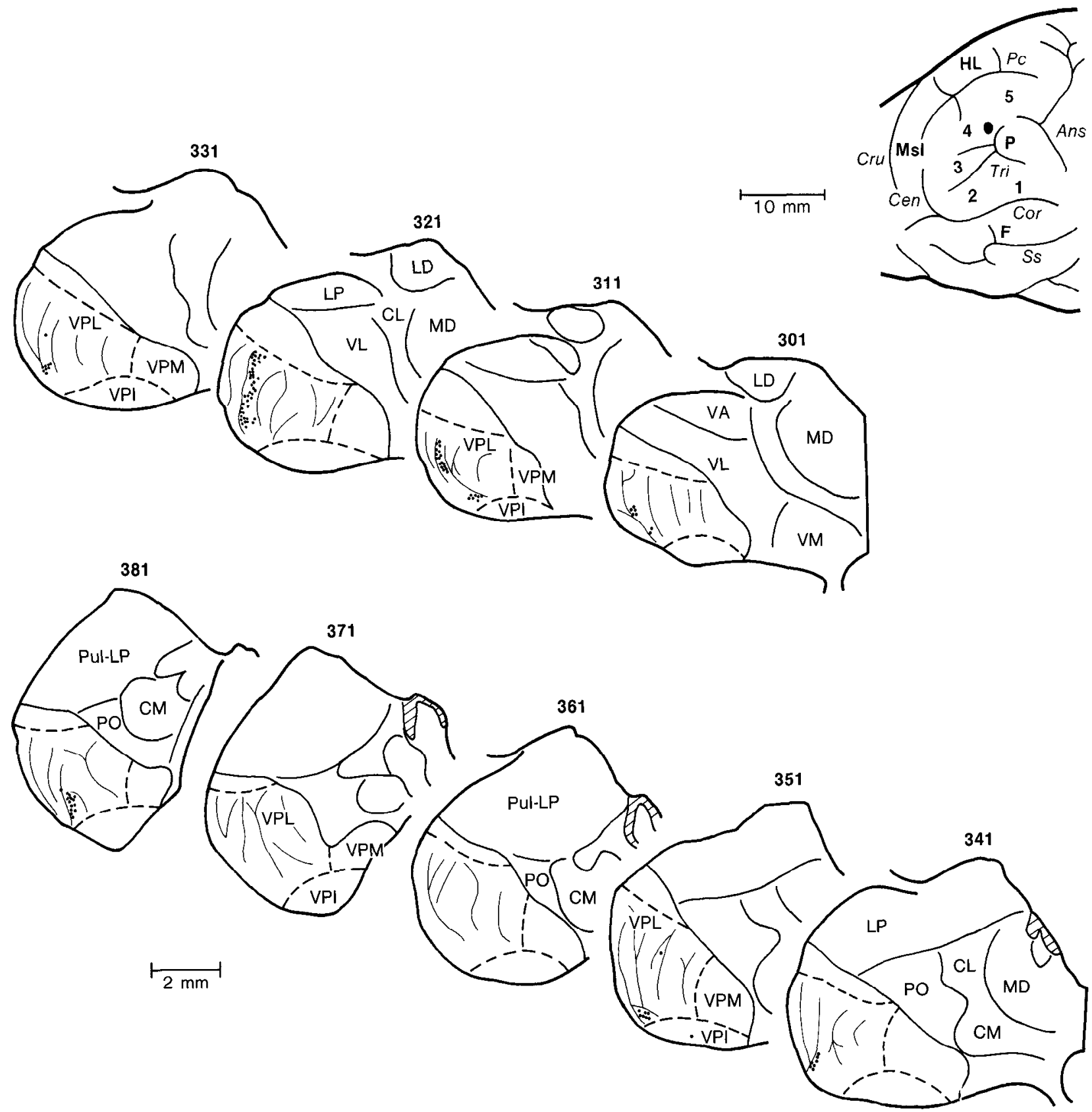

Figure 5. Location of HRP-positive neurons in the thalamus following a small injection into the glabrous sector of the digit 4 cortical area. Section thickness, $50 \mu \mathrm{m}$; distance between sections, $500 \mu \mathrm{m}$. Note the clustering of labeled cells in the digit 4 subnucleus of VPL and the discontinuity of labeling posteriorly (sections 361 and 371 ).

to the basic lamellar organization of VPL. The salient feature revealed by these patterns was the topographic specificity of the connections between a particular glabrous subdivision and the corresponding digit subnucleus of VPL; the labeling was dense and concentrated in one VPL lamella, with very little or no overlap into adjacent lamellae (Figs. 3-5).

The connections between VPL subnuclei and SmI cortical digit areas were found to be reciprocal; a given subnucleus contained both HRP-filled thalamocortical projection neurons and corticothalamic axon terminals originating from neurons located within the cortical injection site (Figs. 6, 7). The larger HRP injections resulted in extensive labeling of neurons and axon terminals within a given subnucleus (Fig. 3). Smaller injections produced equally dense but more restricted labcling in the rostrocaudal and dorsoventral dimensions of the subnucleus (Figs. $4,5)$. Typically, there was a shift in the locations of HRPpositive neurons and axon terminals from dorsal to more ventral sites as a function of distance from rostral to caudal within a given lamella (Figs. 4, 5). Especially with smaller injections, the labeled cells and terminals were often arranged in several dorsoventrally distributed, discontinuous clusters (Figs. 4, 5). Some of these clusters seemed to form elongated, rostrocaudally oriented patches, although obvious gaps were occasionally present in the anteroposterior distribution of the labeling (see sections 361 and 371 of Fig. 5). In most cases, the clusters of HRPpositive neurons and terminals overlapped considerably, but 


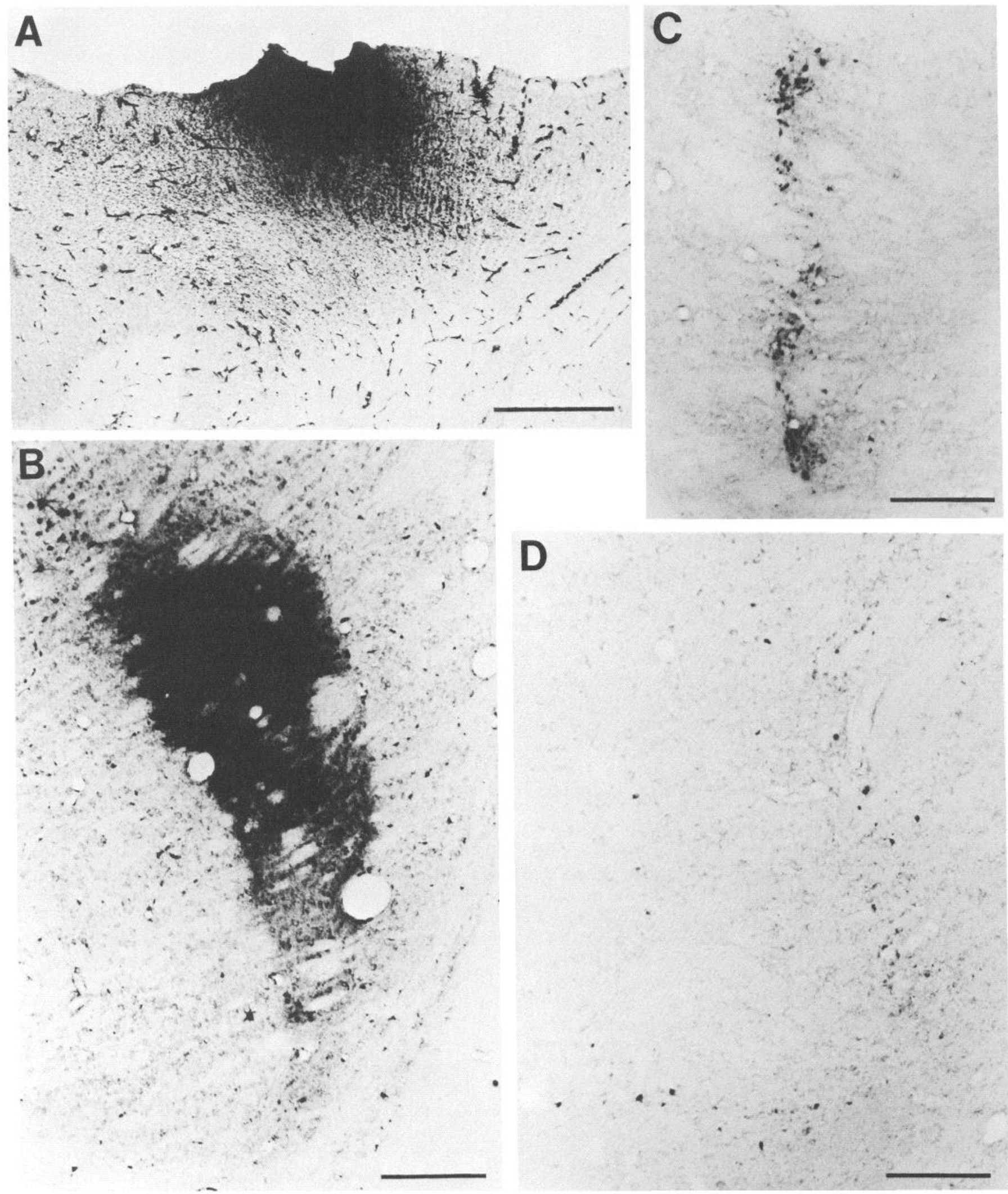

Figure 6. Photomicrographs showing a representative HRP injection site within SmI cortex and different patterns of HRP labeling in VPL. A, Typical HRP injection made in the heterogeneous subdivision of the digit 4 cortical area of the right hemisphere (see Fig. 8); scale, 1 mm. B, Densely labeled neurons and axon terminals in the digit 5 subnucleus of the right VPL resulting from an HRP injection into the glabrous subdivision of the ipsilateral digit 5 cortical zone (see Fig. 3); scale, $0.5 \mathrm{~mm}$. $C$, Clustered distribution of HRP-positive neurons and axon terminals in the digit 4 subnucleus of the left VPL following a small injection into the glabrous region of the ipsilateral digit 4 cortical area (see Fig. 5); scale, 0.5 mm. $D$, Scattered HRP-filled neurons in the right VPL produced by a small injection, illustrated in Figure $6 \mathrm{~A}$, made into the heterogeneous sector of the ipsilateral digit 4 cortical zone. Labeled cells appear to extend from the lateral regions of the digit 4 VPL subnucleus ventrally and then dorsally into the digit 3 subnucleus; scale, $0.5 \mathrm{~mm}$. 

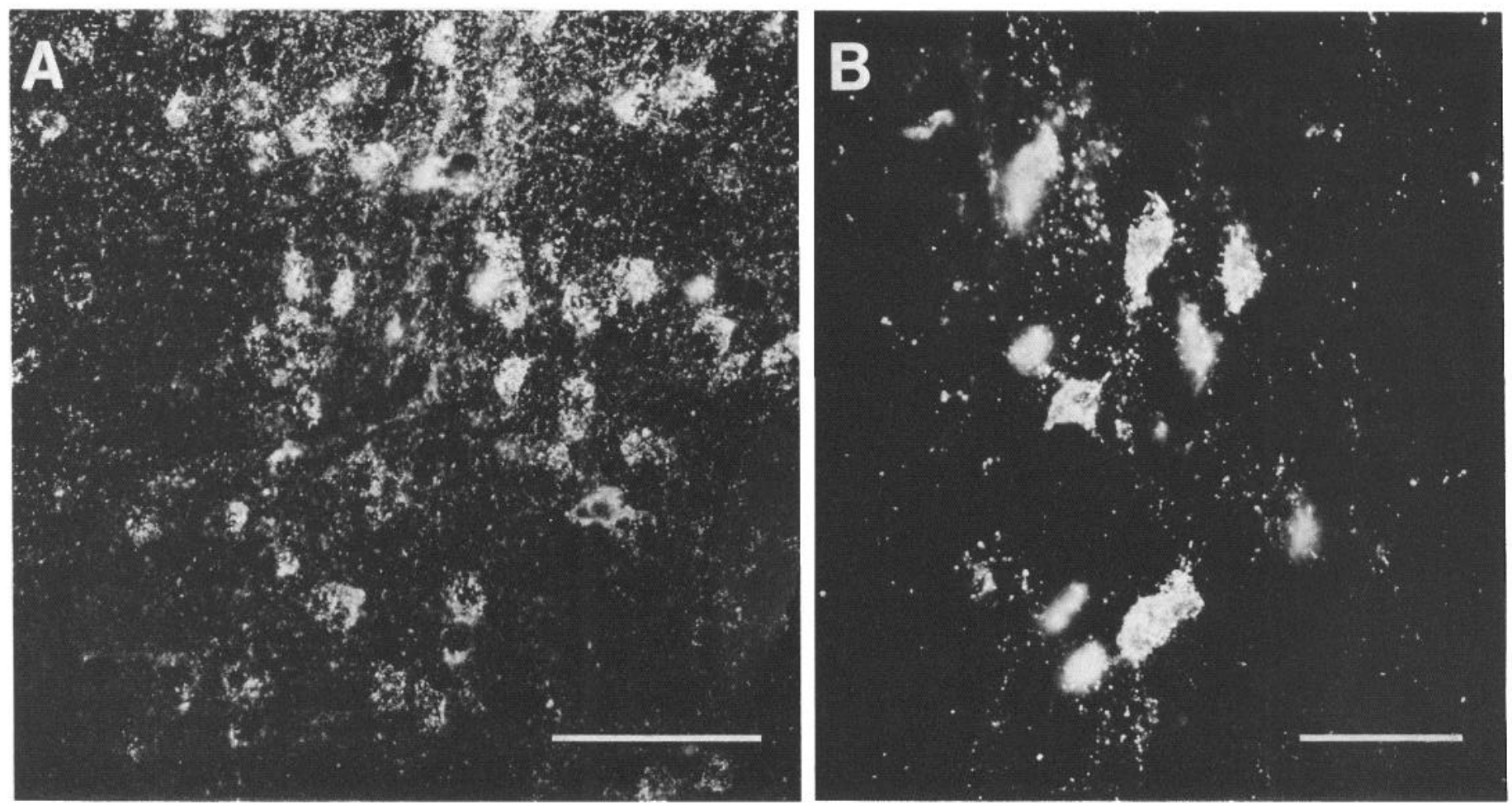

Figure 7. High-power photomicrographs showing HRP-filled neurons and axon terminals (neuropil) in VPL. A, Portion of an extensive aggregate of densely labeled neurons and overlapping axon terminals in the digit 2 VPL subnucleus resulting from a large HRP injection into the glabrous subdivision of the ipsilateral digit 2 cortical zone (see Fig. 2); scale, $100 \mu \mathrm{m}$. B, Small cluster of HRP-labeled neurons and axon terminals in the digit 4 VPL subnucleus following a small HRP injection into the glabrous region of the ipsilateral digit 4 cortical area (see Fig. 5); scale, $50 \mu \mathrm{m}$.

sometimes they were segregated from one another. In general, the rostrocaudal distance over which labeling was distributed within the VPL subnuclei varied from about 1.5 to $4.0 \mathrm{~mm}(\bar{x}=$ $2.6 \mathrm{~mm})$. Finally, no clear distinction was found in the size distributions of labeled and unlabeled neurons in a particular digit subnucleus; HRP-filled neurons included both large (30$20 \mu \mathrm{m})$ and small $(20-10 \mu \mathrm{m})$ cells.

Although the predominant thalamic connections of the glabrous cortical sectors were with the appropriate VPL subnuclei, very sparse interconnections with other thalamic areas were occasionally observed. In one case, labeling was found in the dorsal, presumed kinesthetic region of VPL, appearing as a separate cluster of HRP-positive neurons and axon terminals (see section 411 of Fig. 3). A few scattered HRP-filled cells were located in the ventral posterior inferior (VPI) nucleus (see section 351 of Fig. 5). None were found in the posterior (PO) nucleus or in the intralaminar nuclei. In general, the HRP labeling in thalamic regions other than the appropriate VPL subnucleus was very sparse.

\section{Thalamic connections of heterogeneous cortical subdivisions}

Following small (0.01-0.04 $\mu$ l) injections of HRP into the electrophysiologically defined heterogeneous cortical subdivisions, the resulting thalamic labeling differed from that produced by injections into the glabrous cortical subdivisions. The major thalamic connections of the heterogeneous sectors were with the appropriate subnuclei of VPL. However, 2 distinctive features of the heterogeneous cortical connections was their comparative sparseness and lack of topographic precision as shown by the more widely distributed nature of their thalamic connections (Figs. 8-10).
The projections of the heterogeneous cortical sectors had the following characteristics in common with those of the glabrous sectors. The connections with the VPL subnuclei were reciprocal; HRP-filled neurons and axon terminals formed overlapping clusters or aggregates. The amount of labeling increased with the size of the cortical injection, and the locations of the HRP-positive cells and terminals tended to shift ventrally within the more caudal regions of the VPL lamellae.

The projections of the heterogeneous subdivisions differed from those of the glabrous subdivisions in several respects. After a small injection of HRP into a heterogeneous region, HRPpositive neurons and axon terminals were not confined exclusively to the appropriate VPL subnucleus. Instead, the labeled cells and terminals tended to straddle one or both borders of the primary lamella related to the glabrous subdivision of the injected cortical digit area (Figs. 8-10). Furthermore, the labeling, although less dense, typically extended across these boundaries into adjacent lamellae, involving 2 or even 3 different digit subnuclei within VPL (Figs. 8-10). Thus, the heterogeneous sector of a given cortical digit zone received projections from, and sent projections to, more than one VPL subnucleus. The labeled neurons and axon terminals formed smaller clusters that were more widely scattered throughout VPL than those observed following injections of the glabrous sectors (Figs. 8-10). Indeed, labeling was found in seemingly unrelated portions of VPL, near its dorsal, ventral, or medial borders. Also, the labeling extended caudally into more posterior regions of VPL (Figs. 8-10), although discontinuities sometimes occurred in the anteroposterior distribution of the labeled neurons and terminals (see section 351 of Fig. 9). The rostrocaudal extent of labeling within VPL varied from about 4.5 to 


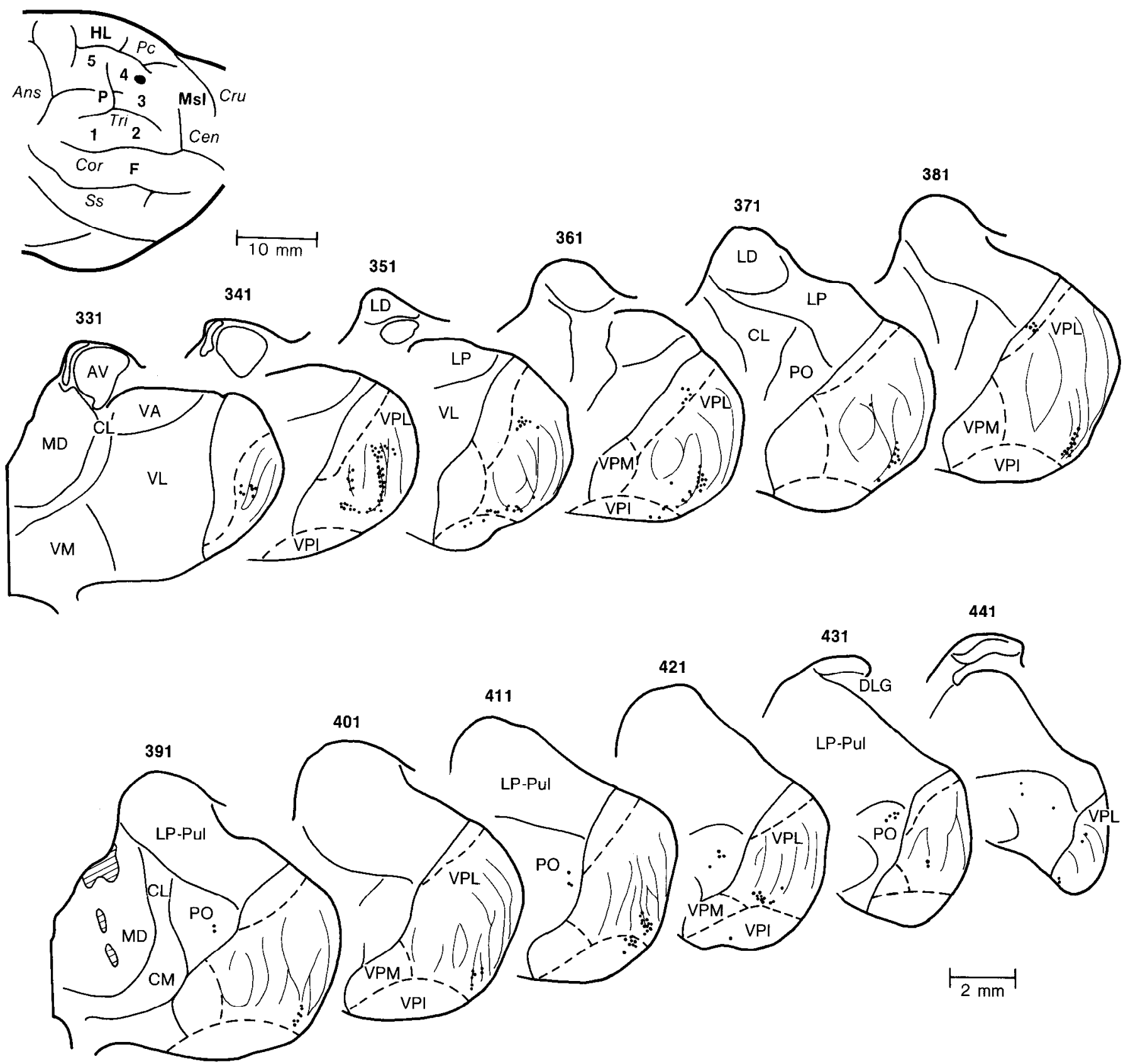

Figure 8. Distribution of labeled neurons in the thalamus resulting from a small HRP injection into the heterogeneous subdivision of the digit 4 cortical zone (see Fig. $6 A$ ). Section thickness, $50 \mu \mathrm{m}$; distance between sections, $500 \mu \mathrm{m}$. HRP-positive cells are found within the digit 4 subnucleus and also in adjoining subnuclei of VPL, especially near the lamellar borders. Small clusters of labeled neurons appear in the presumed kinesthetic region of VPL and others extend ventrally from VPL into VPI. Sparse groups of labeled cells are found in PO.

$5.5 \mathrm{~mm}(\bar{x}=5.0 \mathrm{~mm})$. Thus, the VPL cells projecting to the heterogeneous cortical subdivisions widely loosely distributed over distances about twice as great as those of the more densely packed cells projecting to the glabrous subdivisions.

Labeling outside the subnuclei of VPL was much more common following HRP injections of the heterogeneous subdivisions. More clusters of HRP-positive cells and axon terminals were present dorsally in the presumed kinesthetic region of VPL (Figs. 8-10). In all cases, groups of labeled neurons and axon terminals were found in VPI, sometimes appearing to form ventral extensions of regions labeled within an adjacent VPI, lamella (Figs. 8-10). Unlike the situation following glabrous cortical injections, scattered labeling was consistently observed in PO (Figs. 8-10). However, none was found in the intralaminar nuclei.

\section{Discussion}

The 2 major functional subdivisions of the $\mathrm{SmI}$ forepaw cortex of the raccoon were found to have characteristically different patterns of thalamic interconnectivity. The glabrous skin cortical regions had specific and well-defined connections with the VPL nucleus, consistent with the original description of these thalamocortical relationships by Welker and Johnson (1965). The projections were reciprocal and highly topographic; the glabrous sector of each cortical digit zone was interconnected with its somatotopically corresponding VPL digit subnucleus. 


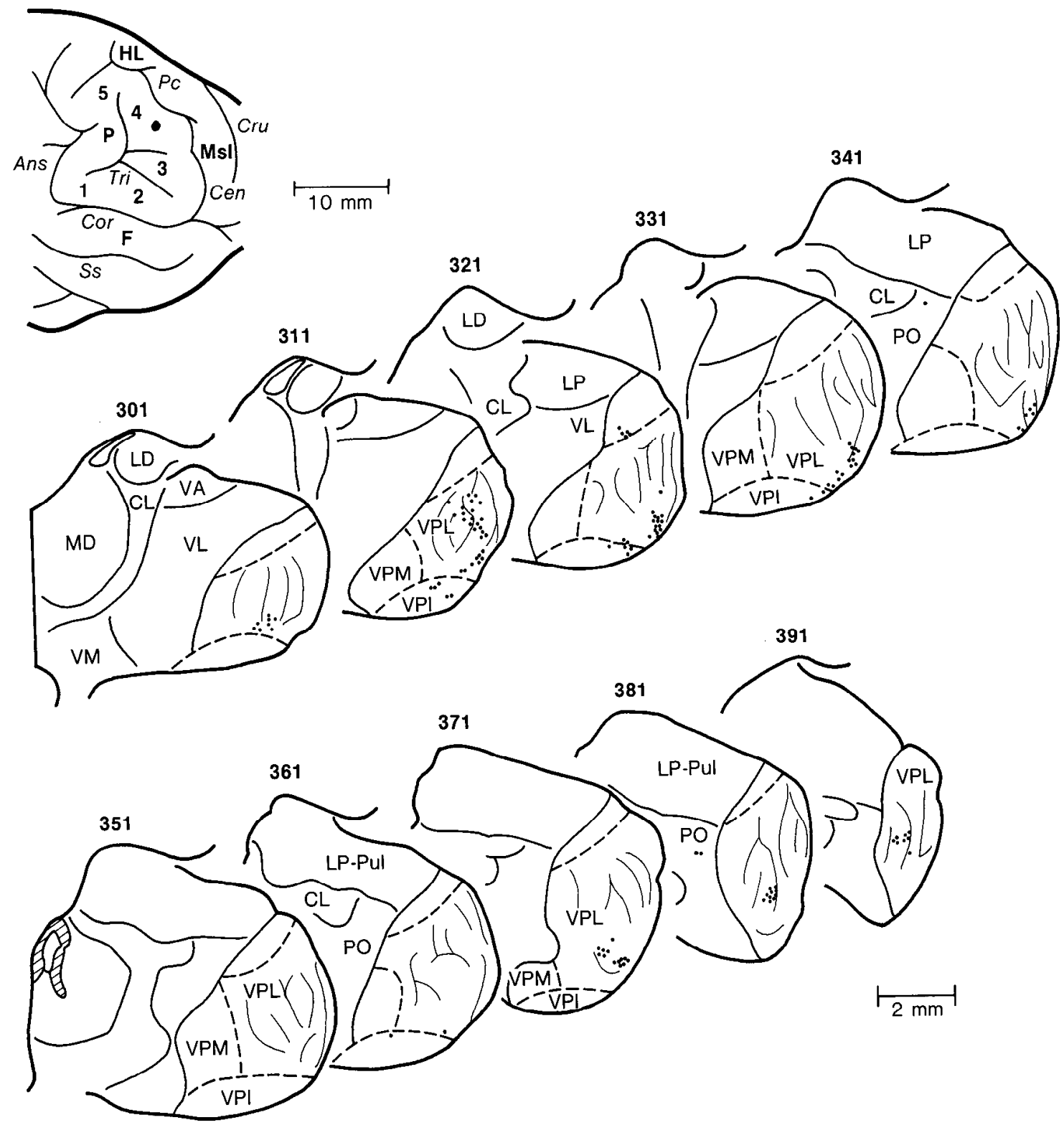

Figure 9. Location of HRP-filled neurons in the thalamus following a small injection into the heterogeneous sector of the digit 4 cortical area. Section thickness, $50 \mu \mathrm{m}$; distance between sections, $500 \mu \mathrm{m}$. Note the scattered and discontinuous (section 351 ) labeling in several digit subnuclei and the dorsal presumed kinesthetic rcgion of VPL. Labeled cells are also present in VPI, and a few are located in PO.

In contrast, the heterogeneous cortical regions had reciprocal thalamocortical interconnections that were considerably less dense and less specific, involving more widely scattered regions of the thalamus. The heterogeneous sector of a cortical digit zone typically received convergent projections from more than one VPL digit subnucleus, from the dorsal presumed kinesthetic region of VPL and from portions of VPI and PO. Hence, the glabrous skin projections were reciprocal and topographically specific, whereas the heterogeneous, hairy skin and claw projections were also reciprocal but more diffuse and convergent. The major features of the 2 types of interconnections are illustrated in Figure 11.

Thalamocortical relationships in the raccoon and other species Differential thalamocortical projection patterns for glabrous skin versus heterogencous, hairy skin and claw representations with- in SmI cortex have not becn described previously in any species. However, the thalamic connections of the glabrous cortical subdivisions were found to be consistent with the results of earlier studies in the raccoon. For example, Herron (1983) and Warren and Pubols (1984) recently employed the HRP method to confirm the discrete and orderly thalamocortical connections that were discovered in the raccoon by Welker and Johnson (1965). Furthermore, Rasmusson and Nance (1986), using the doublefluorescent dye technique, concluded that a single VPL subnucleus projects exclusively to one cortical subgyrus, with no collateralization to adjoining cortical digit zones. This finding is in agreement with the topographic relationships demonstrated in the present study between individual glabrous cortical sectors and VPL subnuclei.

However, the somatotopic organization within a particular VPL digit subnucleus was not entirely clear. Even small injections of HRP into the glabrous subdivision of a cortical digit 


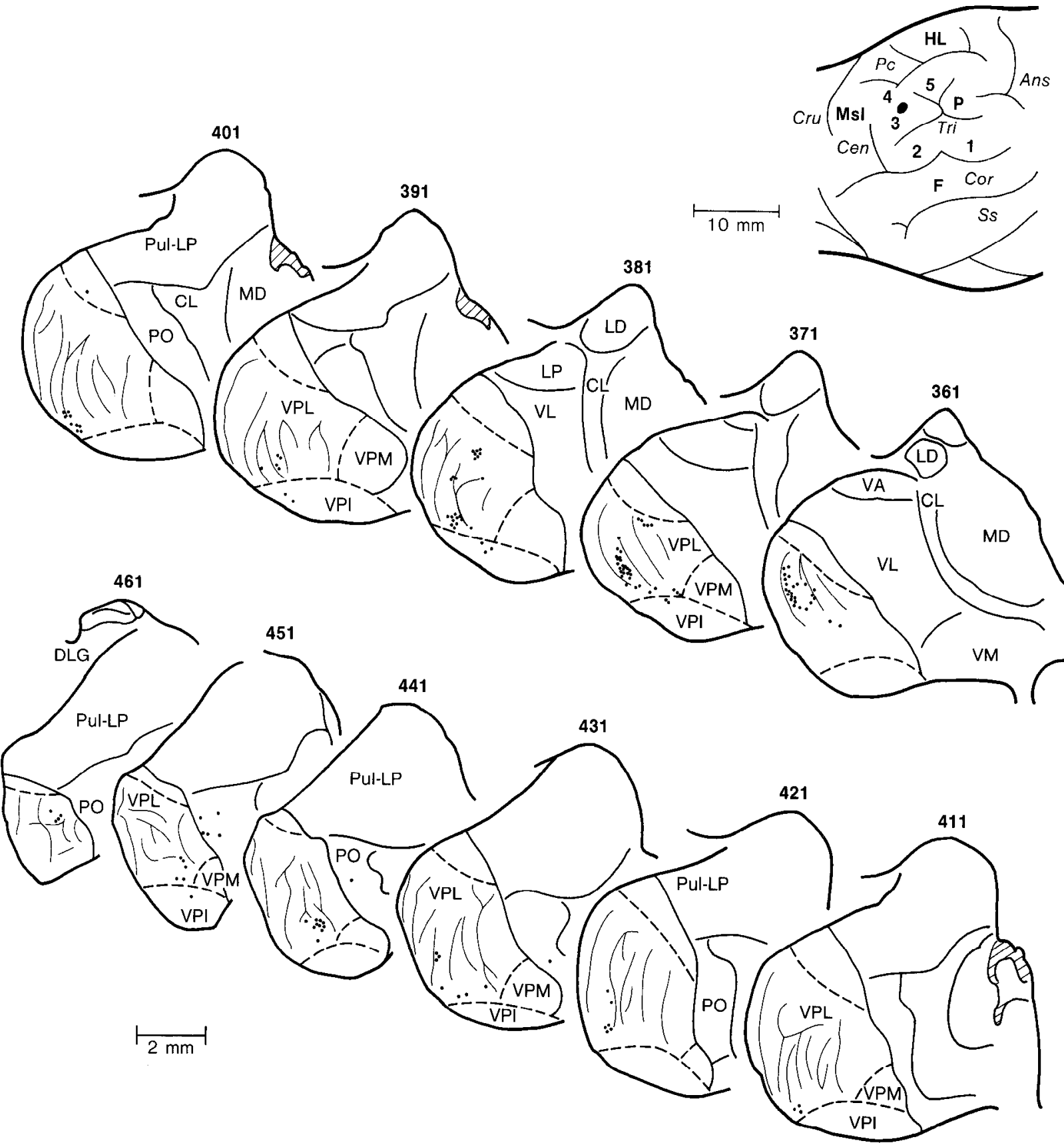

Figure 10. Distribution of labeled neurons in the thalamus following a small injection of HRP into the heterogeneous region at the boundary of the digit 3 and digit 4 cortical zones. Section thickness, $50 \mu \mathrm{m}$; distance between sections, $500 \mu \mathrm{m}$. Aggregates of HRP-filled cells are scattered within several subnuclei of VPL, and a few labeled neurons are located in VPI and PO.

area sometimes resulted in the labeling of clusters of neurons and axon terminals over an extensive dorsoventral portion of the appropriate VPL lamella. This suggests that some convergence and divergence occurs in the interconnections between a given VPL subnucleus and its corresponding cortical digit zone. On the other hand, the tendency of clusters of labeled neurons to extend rostrocaudally for some distance through a lamella may be consistent with the idea of a "rod-like" organization in VPL. Narrow and elongated aggregates of neurons that are believed to receive "place-" and "modality-specific" input seem to extend through VPL of the monkey for distances of nearly 1 mm (Jones et al., 1982; Jones, 1985). Comparable groups of cells in VPL of the cat appear to be considerably shorter (Kosar and Hand, 1981). Whether such rods are present in VPL of the raccoon could not be determined with certainty because consecutive serial sections were not examined for the required anteroposterior continuity of the labeled neuronal clusters. If a rod-like organization does exist, a set of elongated neuronal aggregates might then represent input from somatotopically different regions of a digit-perhaps with separate glabrous and hairy skin or claw RFs - or different functional properties, such as modality sensitivity or adaptation rate. Segregation of VPL neurons into "modality-specific" or "adaptation rate-specific" regions has been reported in the monkey (Dykes et al., 1981) and the cat (Dykes et al., 1986).

Connections of SmI cortex in the raccoon with thalamic re- 


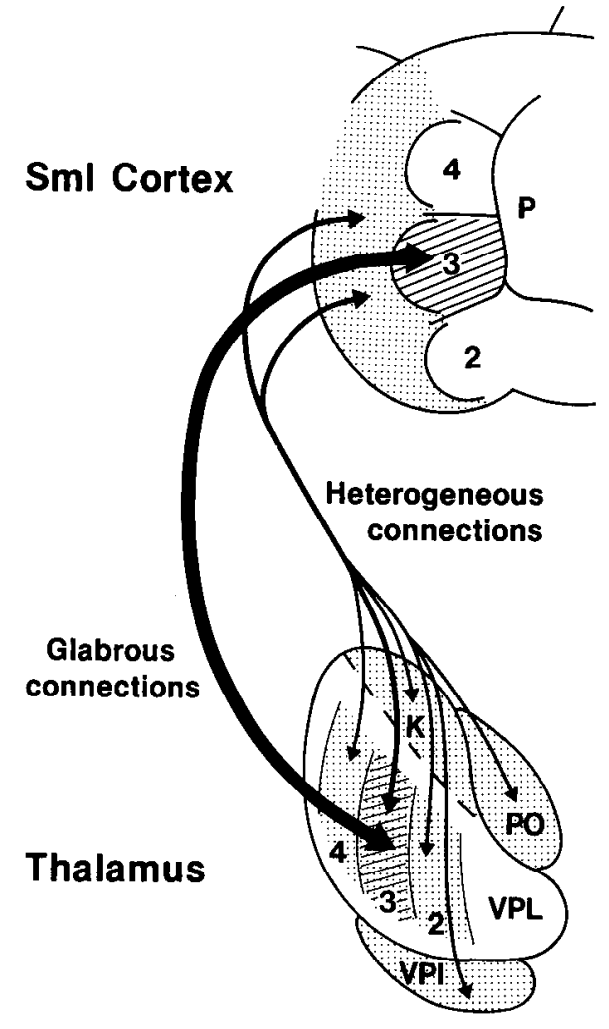

Figure 11. Circuit diagram summarizing the different thalamic interconnections of the glabrous skin and heterogeneous, hairy skin and claw representations of the SmI forepaw digit cortex. To illustrate the dominant features, only the connections of the digit 3 cortical area are shown, but they can be generalized to all other cortical digit areas. The glabrous region (hatched area) of the digit 3 cortical zone has highly topographic, reciprocal connections (thick arrow) with a specific, somatotopically corresponding digit 3 subnucleus (hatched area) in VPL. In contrast, the heterogeneous cortical regions (stippled area) adjoining the glabrous digit 3 zone have relatively diffuse, reciprocal connections (thin arrows) with several distinct nuclear regions (stippled areas) of the thalamus. The strongest interconnections are with the somatotopically appropriate digit 3 subnucleus of VPL, but connections also exist with the adjacent digit 2 and digit 4 VPL subnuclei. The heterogeneous sectors have other interconnections with the presumed kinesthetic $(K)$ region of VPL and portions of VPI and PO. The convergent projections from several thalamic areas to one heterogeneous cortical region can explain many of the diverse functional properties of its constituent neurons.

gions other than VPL have been reported previously, although no attempt was made in earlier studies to distinguish between glabrous and heterogeneous cortical subdivisions. Projections from VPI to SmI cortical digit zones were found by Rasmusson and Nance (1986) but denied by Herron (1983), who concluded that the exclusive cortical target of VPI in the raccoon is the secondary somatosensory (SmII) cortex. Sparse projections from PO to the SmI forepaw cortex were noted by Rasmusson and Nance (1986), as well as by Warren and Pubols (1984). In the present study, VPI and PO were found to have connections almost exclusively with the heterogeneous cortical regions, suggesting that the projections to the glabrous digit representations reported previously were due to spread of the injected tracers into heterogeneous cortical regions. Projections to SmI cortex from VPI and PO have not been found consistently in other species (Jones, 1985).

\section{Anatomical and functional significance of thalamocortical} projections in the raccoon

The differing thalamocortical projections of the glabrous and heterogeneous subdivisions have important implications for the classification and composition of these $2 \mathrm{SmI}$ cortical regions. First, the 2 contrasting projection patterns provide anatomical support for the concept that these subdivisions are functionally distinct cortical regions (Johnson et al., 1982; Kelahan and Doetsch, 1984; Johnson, 1985). Second, they can account for many of the differing functional properties that characterize each subdivision. Thus, the small RFs and modality specificity of neurons within the glabrous cortical sectors can be explained by the discrete topographic projections to these sectors from corresponding modality-specific VPL subnuclei. In contrast, the larger RFs and mixed modality sensitivity of many neurons within the heterogeneous cortical sectors can be accounted for by the more diffuse, convergent projections originating from several VPL subnuclei and adjoining thalamic areas. Third, the differential projections provide clues regarding possible functional subdivisions within VPL and their SmI cortical target areas. While the functional properties of the glabrous skin representations of $\mathrm{SmI}$ cortex can be understood readily in terms of their precise thalamocortical connections, those of the heterogeneous, hairy skin and claw representations could have at least 2 different explanations. The heterogeneous subdivision of each cortical digit zone could receive discrete projections from a separate and distinct heterogeneous subdivision in the thalamus or convergent projections from diverse and functionally different thalamic areas. The present data are more consistent with the latter alternative. This view is supported by the results of a recent electrophysiological mapping study of clusters of neurons in VPL of the raccoon by Wiener et al. (1987). Discontinuous areas representing the hairy skin and claw of a digit apparently were found to be distributed along border regions adjacent to, and partially enclosing, the area containing the glabrous skin representation of that digit in VPL. The hairy skin and claw regions often were intermingled or coextensive with areas receiving input from portions of the glabrous skin or deep tissues. This electrophysiologically defined representational pattern is reminiscent of the present findings that convergent projections to a heterogeneous digit sector originated from the somatotopically corresponding VPL subnucleus-especially its border regions - and from other VPL subnuclei, the kinesthetic region of VPL, and from VPI and PO as well.

These convergent projections strongly suggest the possibility that a heterogeneous cortical region, as currently defined (Johnson et al., 1982; Kelahan and Doetsch, 1984; Johnson, 1985), does not constitute a single, functionally distinct area. Instead, the heterogeneous sector may consist of several circumscribed subregions, each of which might be functionally unique or modality specific - representing hairy skin, claws, and possibly glabrous skin, deep tissues, joints, or some specific combination thereof. Thus, each functional entity might receive specific projections from a discrete region within VPL or surrounding thalamic nuclei, thercby retaining much more topographic order and physiological specificity than is implied by the idea of convergent thalamic projections to one functionally distinct heterogeneous cortical region.

This possibility is compatible with current concepts of the organization of somatosensory thalamocortical relationships in 
mammals, derived primarily from work on monkeys and cats (Dykes, 1983; Kaas, 1983; Johnson, 1985; Jones, 1985). According to this scheme, VPL is comprised of at least 2 major components - a central core region receiving input from cutaneous receptors and a dorsal or rostral shell region receiving input from deep tissues, predominantly muscle and joint afferents (Lin et al., 1979; Jones and Porter, 1980; Dykes et al., 1981, 1986; Maendly et al., 1981; Jones and Friedman, 1982). These 2 principal subdivisions of VPL have different connections with SmI cortex in the monkey; the cutaneous core projects to cytoarchitectonic areas $3 b$ and 1 , whereas the deep shell region projects to areas $3 a$ and 2 . The shell region itself has been subdivided into 2 separate nuclei, a rostral part called the ventral posterior oral (VPO) nucleus projecting to cortical area $3 \mathrm{a}$ and a more caudal portion termed the ventral posterior superior (VPS) nucleus projecting to area 2 (Dykes, 1983; Kaas, 1983; Dykes et al., 1986). In the raccoon, the so-called kinesthetic cortical area-located between MsI cortex and the heterogeneous region of SmI cortex (Johnson et al., 1982; Feldman and Johnson, 1985; Johnson, 1985)-has functional properties similar to those of area $3 \mathrm{a}$ in the monkey and cat; it receives input from muscle and joint receptors via a separate kinesthetic region of VPL (Johnson, 1985; Wiener et al., 1987). This strongly suggests that the kinesthetic region of VPL is homologous with VPO of other species and may be classified as an anatomically and functionally distinct nucleus specifically interconnected with kinesthetic cortical area $3 \mathrm{a}$.

In the present study, injections of HRP into a heterogeneous cortical region often labeled clusters of neurons in the dorsal kinesthetic portion of VPL (or VPO). This finding indicates that the heterogeneous cortex of the raccoon may contain a subregion that is part of area $3 \mathrm{a}$ proper or that constitutes a separate functional cortical area related to kinesthetic input. In any case, VPL of the raccoon consists of cutaneous and deep (kinesthetic) components, similar to those of the monkcy and cat, that project to functionally different cortical areas (Johnson, 1985; Wiener et al., 1987). Detailed single-neuron recordings and discrete anatomical tracer studies are required to determine whether the heterogeneous cortex can be subdivided and whether corresponding thalamic subdivisions exist.

\section{Cerebral plasticity and thalamocortical connectivity}

As described above, the unique thalamocortical projections to the 2 major functional subdivisions of SmI cortex of the raccoon can account for many of the normal functional properties of neurons located within each subdivision. However, these projections do not explain the diverse response properties that appear within the glabrous sector of a cortical digit zone following peripheral nerve transection because no convergent projections from multiple VPL subnuclei into a glabrous cortical sector were found. Hence, additional anatomical circuitry must be present to permit convergent input to reach the glabrous subdivisions. For example, intracortical projections from the heterogeneous cortical regions into the glabrous region of a particular digit zone could mediate the observed effects. The action of the convergent projections from the thalamus to the heterogeneous cortical sectors could then contribute indirectly to the emergence of new responses in a reactivated glabrous cortical digit area. Intracortical connections that may provide the basis for such circuits are described in the following paper (Doetsch ct al., 1988).

\section{Appendix}

Nomenclature and abbreviations

$\begin{array}{ll}\text { Cortical sulci } & \\ \text { Ans } & \text { ansate } \\ \text { Cen } & \text { central } \\ \text { Cru } & \text { cruciate } \\ \text { Cor } & \text { coronal } \\ \text { Pc } & \text { postcruciate } \\ \text { Ss } & \text { suprasylvian } \\ \text { Tri } & \text { triradiate }\end{array}$

Functional cortical areas

1-5 forepaw digits 1-5

$\mathrm{F}$ face

HL hindlimb

MsI primary motor

$P \quad$ palmar pads

Thalamic nuclei

$\begin{array}{ll}\text { AV } & \text { anterior ventral } \\ \text { CL } & \text { central lateral } \\ \text { CM } & \text { centre median } \\ \text { DLG } & \text { dorsal lateral geniculate } \\ \text { LD } & \text { lateral dorsal } \\ \text { LP } & \text { lateral posterior } \\ \text { MD } & \text { medial dorsal } \\ \text { PO } & \text { posterior } \\ \text { Pul } & \text { pulvinar } \\ \text { VA } & \text { ventral anterior } \\ \text { VL } & \text { ventral lateral } \\ \text { VM } & \text { ventral medial } \\ \text { VPI } & \text { ventral posterior inferior } \\ \text { VPL } & \text { ventral posterior lateral } \\ \text { VPM } & \text { ventral posterior medial }\end{array}$

\section{References}

Carson, L. V., A. M. Kelahan, R. H. Ray, C. E. Massey, and G. S. Doetsch (1981) Effects of early peripheral lesions on the somatotopic organization of the cerebral cortex. In Clinical Neurosurgery, Vol. 28, P. W. Carmel, ed., pp. 532-546, Williams \& Wilkins, Baltimore.

Craig, A. D., and H. Burton (1985) The distribution and topographical organization in the thalamus of anterogradely-transported horseradish peroxidase after spinal injections in cat and raccoon. Exp. Brain Res. 58: 227-254.

Doetsch, G. S., K. W. Johnston, C.-S. Lin, and G. P. Standage (1988) Intracortical connections of two functional subdivisions of the somatosensory forepaw cerebral cortex of the raccoon. J. Neurosci. 8: $1887-1900$.

Dykes, R. W. (1983) Parallel processing of somatosensory information: A theory. Brain. Res. Rev. 6: 47-115.

Dykes, R. W., M. Sur, M. M. Merzenich, J. H. Kaas, and R. J. Nelson (198I) Regional segregation of neurons responding to quickly adapting, slowly adapting, deep and Pacinian receptors within thalamic ventroposterior lateral and ventroposterior inferior nuclei in the squirrel monkey (Saimiri sciureus). Neuroscience 6: 1687-1692.

Dykes, R. W., P. Herron, and C.-S. Lin (1986) Ventroposterior thalamic regions projecting to cytoarchitectonic areas $3 \mathrm{a}$ and $3 \mathrm{~b}$ in the cat. J. Neurophysiol. 56: 1521-1541.

Feldman, S. H., and J. I. Johnson (1985) The kinesthetic cortical area anterior to primary somatic sensory cortex in the raccoon (Procyon lotor). Anat. Rec. 211: 60A-61A.

Hardin, Jr., W. B., N. Arumugasamy, and H. D. Jameson (1968) Pattern of localization in the "precentral" motor cortex of raccoon. Brain Res. 11: 611-627.

Herron, P. (1983) The connections of cortical somatosensory areas I and II with separate nuclei in the ventroposterior thalamus in the raccoon. Neuroscience $8: 243-257$.

Johnson, J. I. (1985) Thalamocortical organization in the raccoon: Comparison with the primate. Exp. Brain Res. Suppl. 10: 294-312.

Johnson, Jr., J. I., W. I. Welker, and B. H. Pubols, Jr. (1968) Soma- 
totopic organization of raccoon dorsal column nuclei. J. Comp. Neurol. 132: 1-44

Johnson, J. I., E.-M. Ostapoff, and S. Warach (1982) The anterior border zones of primary somatic sensory (SI) neocortex and their relation to cerebral convolutions, shown by micromapping of peripheral projections to the region of the fourth forepaw digit representation in raccoons. Neuroscience 7:915-936.

Jones, E. G. (1975) Possible determinants of the degree of retrograde neuronal labeling with horseradish peroxidase. Brain Res. 85: 249253.

Jones, E. G. (1985) The Thalamus, Plenum, New York

Jones, E. G., and D. P. Friedman (1982) Projection pattern of functional components of thalamic ventrobasal complex on monkey somatosensory cortex. J. Neurophysiol. 48: 521-544.

Jones, E. G., and R. Porter (1980) What is area 3a? Brain Res. Rev. 2: $1-43$.

Jones, E. G., D. P. Friedman, and S. II. C. IIendry (1982) Thalamic basis of place- and modality-specific columns in monkey somatosensory cortex: A correlative anatomical and physiological study. J. Neurophysiol. 48: 545-568.

Kaas, J. H. (1983) What, if anything, is SI? Organization of first somatosensory area of cortex. Physiol. Rev. 63: 206-231.

Kelahan, A. M., and G. S. Doetsch (1984) Time-dependent changes in the functional organization of somatosensory cerebral cortex following digit amputation in adult raccoons. Somatosens. Res. 2: 4981.

Kelahan, A. M., R. H. Ray, L. V. Carson, C. E. Massey, and G. S. Doetsch (1981) Functional reorganization of adult raccoon somatosensory cerebral cortex following neonatal digit amputation. Brain Res. 223: 151-159.

Kosar, E., and P. J. Iland (1981) First somatosensory cortical columns and associated neuronal clusters of nucleus ventralis posterolateralis of the cat: An anatomical demonstration. J. Comp. Neurol. 198:515539.

Lin, C.-S., M. M. Merzenich, M. Sur, and J. H. Kaas (1979) Connections of areas $3 \mathrm{~b}$ and 1 of the parietal somatosensory strip with the ventroposterior nucleus in owl monkey (Aotus trivirgatus). J. Comp. Neurol. 185: 355-371.
Maendly, R., D. G. Ruegg, M. Wiesendanger, R. Wiesendanger, J. Lagowska, and B. Hess (1981) Thalamic relay for group I muscle afferents of forelimb nerves in the monkey. J. Neurophysiol. 46:901917.

Mesulam, M.-M. (1978) Tetramethyl benzidine for horseradish peroxidase neurohistochemistry: A non-carcinogenic blue reaction product with superior sensitivity for visualizing neural afferents and efferents. J. Histochem. Cytochem. 26: 106-117.

Rasmusson, D. D. (1982) Reorganization of raccoon somatosensory cortex following removal of the fifth digit. J. Comp. Neurol. 205:313326.

Rasmusson, D. D., and D. M. Nance (1986) Non-overlapping thalamocortical projections for separate forepaw digits before and after cortical reorganization in the raccoon. Brain Res. Bull. 16: 399-406

Rasmusson, D. D., B. G. Turnbull, and C. K. Leech (1985) Unexpected reorganization of somatosensory cortex in a raccoon with extensive forelimb loss. Neurosci. Lett. 55: 167-172.

Ray, R. H., and G. S. Doetsch (1977) Observations on the pyramidal system of the North American raccoon (Procyon lotor). Soc. Exp. Biol. Med. 2: 2 (abstr.).

Sakai, S. T. (1982) The thalamic connectivity of the primary motor cortex (MI) in the raccoon. J. Comp. Neurol. 204: 238-252.

Warr, W. B., J. S. de OImos, and L. Heimer (1981) Horseradish peroxidase. The basic procedure. In Neuroanatomical Tract-tracing Methods, L. Heimer and M. J. Robards, eds., pp. 207-262, Plenum, New York.

Warren, S., and B. H. Pubols, Jr. (1984) Somatosensory thalamocortical connections in the racoon: An HRP study. J. Comp. Neurol. 227: 597-606.

Welker, W. I., and J. I. Johnson, Jr. (1965) Correlation between nuclear morphology and somatotopic organization in ventrobasal complex of the raccoon's thalamus. J. Anat. 99: 761-790.

Welker, W. I., and S. Seidenstein (1959) Somatic sensory representation in the cerebral cortex of the racoon (Procyon lotor). J. Comp. Neurol. 111: 469-501.

Wiener, S. I., J. I. Johnson, and E.-M. Ostapoff (1987) Organization of postcranial kinesthetic projections to the ventrobasal thalamus in raccoons. J. Comp. Neurol. 258: 496-508. 